Article

\title{
Novel Lipidized Derivatives of the Bioflavonoid Hesperidin: Dermatological, Cosmetic and Chemopreventive Applications
}

\author{
Alessia Bino ${ }^{1}$, Chiara Beatrice Vicentini ${ }^{1}$, Silvia Vertuani ${ }^{1,2, *}$, Ilaria Lampronti ${ }^{1}{ }^{(1)}$, \\ Roberto Gambari ${ }^{1}$, Elisa Durini ${ }^{1}$, Stefano Manfredini ${ }^{1,2}$ (D) and Anna Baldisserotto ${ }^{1}$ (D) \\ 1 Department of Life science and Biotechnology, University of Ferrara, 44121 Ferrara, Italy; \\ bnills@unife.it (A.B.); vcc@unife.it (C.B.V.); lmi@unife.it (I.L.); gam@unife.it (R.G.); dre@unife.it (E.D.); \\ mv9@unife.it (S.M.); bldnna@unife.it (A.B.) \\ 2 AMBROSIALAB srl, 44121 Ferrara, Italy \\ * Correspondence: vrs@unife.it; Tel.: +39-0532-455294
}

Received: 9 November 2018; Accepted: 12 December 2018; Published: 15 December 2018

\begin{abstract}
Hesperidin is one of the most important natural flavonoids, known for its antioxidant, anti-inflammatory, anti-mutagenic, and anti-hypertensive properties. Despite its various biological activities, hesperidin is rarely used in the dermo-cosmetic field because of its poor solubility in both water and oil phases that makes difficult formulation, distribution and bioavailability through the skin layers. Moreover, hesperidin is still underestimated in skin care products, and literature data on its stability into a topical formulation are not yet available. In this paper we report the synthesis of five different derivatives of hesperidin and their evaluation in terms of antioxidant, antifungal, antiproliferative, and apoptotic effects on human leukemic K562 cells. Preliminary antiproliferative effects were considered since hyper-proliferation is involved in several cutaneous problems particularly in the case of photo-exposition and environmental pollution. Esp4 and Esp5 were found to be more active in inhibiting K562 cell growth than parent hesperidin. Esp3 exhibited different biological properties, i.e., antioxidant activity in the absence of antiproliferative effects.
\end{abstract}

Keywords: hesperidin; antioxidant; pro-apoptotic; antifungal; dermo-cosmetic

\section{Introduction}

Among phenolic compounds, flavonoids represent one of the most important classes [1]. These molecules are commonly found in different plant materials such as fruit, herbs, vegetables, and cereals [2]. Flavonoids display many different biological activities. Antioxidant, photo-protective, photo-aging, anti-inflammatory, metal-chelating, anti-allergic, and anti-bacterial are the most important flavonoid-mediated activities on the skin [3-6]. Hesperidin is a flavanone glycoside abundant in citrus fruit peel [7], it is formed by the aglycone also called "hesperetin" to which a 6-O- $\alpha$-L-rhamnosyl-D-glucose in position seven is bound. Since its discovery in 1872 by Lebreton, hesperidin became the object of continuous research focusing on both extraction methods and biological/biomedical activities [8].

Hesperidin has many biological activities, displaying antioxidant, prostaglandin-synthesis inhibitory, anti-inflammatory, and anti-mutagenic effects [9-12]. The recent interest in the use of flavonoids as anti-cancer agents has highlighted the effects of hesperidin in prevention and treatment of various human diseases [13-15]. Among the many beneficial effects on health, it has been reported that hesperidin is able to inhibit skin tumorigenesis [16].

With respect to structure activity relationships, the main biological activities of hesperidin, such as the antioxidant power, are closely associated with the chemical structure of the aglycone [17]. 
Although appealing for biomedical applications, flavonoids have general problems in terms of bioavailability, stability, and formulation [18]. Literature data about the pharmacokinetics of dietary flavonoids are widely discussed, but studies about the skin absorption of all these natural molecules are not yet available [19]. Glycosylated flavonoids are subjected to fibroblast glucosidases activity, leading to the release of pharmacologically active aglycone moiety [20]. Moreover, glycosylated drugs have low cellular toxicity as compared to their aglycones [21].

Skin absorption is a multifactorial and complex process considering that skin is the first barrier against biological toxins, and is designed to reduce water loss [22]. A topical effective molecule must cross the outer skin layers (first the stratum corneum and then the epidermis or using alternative routes such are glands and interstitial passages) and subsequently might stay within the papillary dermis to have its local effect. Conversely, achieving a systemic circulation by a topical molecule is considered a side effect [23]. The Log P value of the molecule is one of the most important factors to allow skin absorption. The Log $\mathrm{P}$ value indicates the rough estimate capacity to permeate directly across skin layers. Since the stratum corneum is constituted up of ceramides, cholesterol, and fatty acids, an hydrophilic molecule cannot efficiently penetrate the skin [24,25]. Hesperidin and many natural flavonoids do not have enough lipophilic molecules to cross the skin [26]. On the other hand, hesperidin is also poorly soluble in water [27]. These solubility problems reduce its skin topical use due to the difficulty in formulation, and consequently poor availability for skin [28,29]. Therefore, despite its various biological activity, hesperidin is still underestimated in skin care products, and literature data on its stability into a topical formulation are not yet available.

In the present study, continuing our investigation on phenylpropanoid structures [30-32], we synthetized lipophilic ester derivatives of hesperidin in order to improve its stability in topical formulations and in finished cosmetic products.

Moreover, following our recent approach, aimed to investigate newly synthesized molecules, possibly endowed with multifunctional properties, preliminary antioxidant, antimicrobial, anti-proliferative, and apoptosis induction tests were performed because all of this might allow a preventive role for such a class of molecules, that might be useful for early ageing and oxidative damage prevention, especially when considering daily cosmetic use.

\section{Materials and Methods}

\subsection{General}

All reagents and solvents were supplied by Sigma-Aldrich, Milan, Italy and CARLO ERBA Reagents, Milan, Italy. ${ }^{1} \mathrm{H}$ NMR spectra were recorded on VXR-200 Varian spectrometer and Mercury Plus-400 in d6-DMSO. Chemical shift values are expressed in ppm using tetramethylsilane as the reference standard (TMS). UV spectra were recorded on a UV-VIS spectrophotometer (Shimadzu UV-2600, Shimadzu Italia, Milano, Italia). HPLC analysis was performed using an Agilent 1100 Series HPLC System equipped with a G1315A DAD, autosampler and with a Phenomenex Synergi Hydro-RP C18 $80 \AA$ column $(4.6 \times 150 \mathrm{~mm}, 4 \mu \mathrm{m})$.

\subsection{Chemistry}

\subsubsection{Synthesis of Epta-Tert-Butyl Hesperidin (Esp1)}

To a solution of hesperidin $(0.64 \mathrm{mmol})$ and DMAP $(23.04 \mathrm{mmol})$ in $\mathrm{CH}_{2} \mathrm{Cl}_{2}(40 \mathrm{~mL})$, tert-butyl-acetyl chloride $(17.28 \mathrm{mmol})$ was added. The reaction mixture was stirred for $14 \mathrm{~h}$ at room temperature and then washed with $\mathrm{H}_{2} \mathrm{O}, \mathrm{NaHCO}_{3}$ and Brine. The combined organic phases were dried and evaporated under reduced pressure. The crude residue was purified by column chromatography (ethyl acetate) to obtain Esp1 as orange oil (yield 65.25\%). ${ }^{1} \mathrm{H}-\mathrm{NMR}$ (DMSO) $\delta$ ppm: 0.96 to $1.03(\mathrm{~m}, 66 \mathrm{H}) ; 2.06$ to $2.12(\mathrm{~m}, 12 \mathrm{H}) ; 2.43(\mathrm{~m}, 2 \mathrm{H}) ; 2.50(\mathrm{~m}, 2 \mathrm{H}) ; 2.70(\mathrm{~m}, 1 \mathrm{H}) ; 3.30(\mathrm{~m}, 2 \mathrm{H}) ; 3.59$ to $3.61(\mathrm{~m}, 2 \mathrm{H}) ; 3.80(\mathrm{~s}, 3 \mathrm{H}) ; 4.30(\mathrm{t}, 1 \mathrm{H}) ; 5.10(\mathrm{~m}, 4 \mathrm{H}) ; 5.43(\mathrm{~d}, 1 \mathrm{H}) ; 5.50-5.60(\mathrm{~m}, 1 \mathrm{H}) ; 5.80(\mathrm{~d}, 1 \mathrm{H}) ; 6.25$ to 
$6.65(\mathrm{~m}, 2 \mathrm{H}) ; 7.15$ to $7.25(\mathrm{~d}, 2 \mathrm{H}), 7.40(\mathrm{~m}, 1 \mathrm{H}) ; 12.00(\mathrm{~s}, 1 \mathrm{H})$. ESI-MS $[\mathrm{M}+\mathrm{H}]^{+}$: found for $\mathrm{C}_{70} \mathrm{H}_{104} \mathrm{O}_{22}$, 1298.56. HPLC purity $99.2 \%$.

\subsubsection{Synthesis of Epta-Cyclohexylacetyl Hesperidin (Esp2)}

To a solution of hesperidin $(0.64 \mathrm{mmol})$ and DMAP $(23.04 \mathrm{mmol})$ in $\mathrm{CH}_{2} \mathrm{Cl}_{2}(40 \mathrm{~mL})$, cyclohexylacetyl chloride $(17.28 \mathrm{mmol})$ was added. After stirring for $14 \mathrm{~h}$ at room temperature, the mixture was washed with water, $\mathrm{NaHCO}_{3}$, and Brine and the organic phase was then dried and concentrated under reduced pressure. The residue was purified by column chromatography (ethyl acetate) to obtain Esp2 (final yield 79.28\%) as orange oil. ${ }^{1} \mathrm{H}-\mathrm{NMR}$ (DMSO) $\delta \mathrm{ppm}: 1.20$ (d, 3H, $\mathrm{CH}_{3}$ ); 1.35 to $1.50(\mathrm{~m}, 70 \mathrm{H}) ; 2.06$ to $2.12,(\mathrm{~m}, 19 \mathrm{H}) ; 2.35(\mathrm{~d}, 2 \mathrm{H}) ; 3.43(\mathrm{~m}, 2 \mathrm{H}) ; 3.50(\mathrm{~m}, 2 \mathrm{H}) ; 3.79(\mathrm{~s}, 3 \mathrm{H}) ; 4.37$ to $4.50(\mathrm{~m}, 2 \mathrm{H}) ; 5.30(\mathrm{t}, 2 \mathrm{H}) ; 5.51$ to $5.62(\mathrm{~m}, 2 \mathrm{H}) ; 5.82(\mathrm{~m}, 1 \mathrm{H}) ; 5.90(\mathrm{~m}, 3 \mathrm{H}) ; 6.23$ to $6.65(\mathrm{~m}, 2 \mathrm{H}) ; 7.12(\mathrm{~d}$, $1 \mathrm{H}), 7.25(\mathrm{~d}, 1 \mathrm{H}), 7.40(\mathrm{~m}, 2 \mathrm{H}) ; 12.00(\mathrm{~s}, 1 \mathrm{H})$. ESI-MS $[\mathrm{M}+\mathrm{H}]^{+}$: found for $\mathrm{C}_{84} \mathrm{H}_{118} \mathrm{O}_{22}, 1480.85$. HPLC purity $99.6 \%$.

\subsubsection{Synthesis of Epta-Benzoyl Hesperidin (Esp3)}

To a solution of hesperidin ( $0.64 \mathrm{mmol})$ and DMAP $(23.04 \mathrm{mmol})$ in $\mathrm{CH}_{2} \mathrm{Cl}_{2}(40 \mathrm{~mL})$, benzoyl chloride $(17.28 \mathrm{mmol}$ ) was added. After stirring at room temperature for $14 \mathrm{~h}$, the reaction mixture was washed with $\mathrm{H}_{2} \mathrm{O}, \mathrm{NaHCO}_{3}$ and Brine. The organic phase was subsequently dried and evaporated under reduced pressure to give a crude residue purified by column chromatography (ethyl acetate). Esp3 was obtained by crystallization from methanol as a light yellow powder (final yield $56.87 \%$ ). ${ }^{1} \mathrm{H}-\mathrm{NMR}$ (DMSO) $\delta$ ppm: $1.10(\mathrm{t}, 3 \mathrm{H}) ; 3.20$ to $3.40(\mathrm{~m}, 2 \mathrm{H}) ; 3.52$ to $3.61(\mathrm{~m}, 2 \mathrm{H}) ; 3.80(\mathrm{~s}, 3 \mathrm{H}) ; 4.28$ to 4.37 $(\mathrm{m}, 2 \mathrm{H}) ; 5.28(\mathrm{t}, 2 \mathrm{H}) ; 5.50$ to $5.61(\mathrm{~m}, 2 \mathrm{H}) ; 5.85$ to $5.96(\mathrm{~m}, 4 \mathrm{H}) ; 6.18(\mathrm{t}, 2 \mathrm{H}) ; 6.39(\mathrm{~d}, 1 \mathrm{H}) ; 6.89(\mathrm{~d}, 1 \mathrm{H})$; $7.32(\mathrm{~m}, 2 \mathrm{H}) ; 7.56$ to $7.71(\mathrm{~m}, 21 \mathrm{H}) ; 8.02(\mathrm{~m}, 12 \mathrm{H}) ; 8.14(8 \mathrm{~d}, 2 \mathrm{H}) ; 12.00(\mathrm{~s}, 1 \mathrm{H}, \mathrm{OH}$ aromatico). ESI-MS $[\mathrm{M}+\mathrm{H}]^{+}$: found for $\mathrm{C}_{77} \mathrm{H}_{62} \mathrm{O}_{22}, 1340.30$. HPLC purity $98.7 \%$.

\subsubsection{Synthesis of Epta-Naphtoyl Hesperidin (Esp4)}

To a solution of hesperidin ( $0.64 \mathrm{mmol})$ and DMAP (23.04 mmol) in $\mathrm{CH}_{2} \mathrm{Cl}_{2}(40 \mathrm{~mL})$, naphthoyl chloride (17.28 $\mathrm{mmol}$ ) was added. The reaction was stirring for $14 \mathrm{~h}$ at room temperature and then washed with $\mathrm{H}_{2} \mathrm{O}, \mathrm{NaHCO}_{3}$ and Brine. The combined organic phase was dried and evaporated under reduced pressure. The crude residue was purified by column chromatography (petroleum ether/ethyl acetate: 50/50) to obtain Esp4 was obtained as white powder (final yield 77.23\%). ${ }^{1} \mathrm{H}-\mathrm{NMR}$ (DMSO) $\delta$ ppm: $1.14(\mathrm{~d}, 3 \mathrm{H}) ; 2.70(\mathrm{~m}, 1 \mathrm{H}) ; 3.30(\mathrm{~m}, 2 \mathrm{H}) ; 3.59-3.61(\mathrm{~m}, 1 \mathrm{H}) ; 3.81(\mathrm{~s}, 3 \mathrm{H}) ; 4.29-4.35(\mathrm{~m}, 2 \mathrm{H}) ; 5.30$ $(\mathrm{t}, 2 \mathrm{H})$; 5.39-5.42 (m, 2H); 5.89-6.02 (m, 4H); $6.18(\mathrm{t}, 2 \mathrm{H}) ; 6.39(\mathrm{~d}, 1 \mathrm{H}) ; 6.91(\mathrm{~d}, 1 \mathrm{H}) ; 7.15-7.25(\mathrm{~m}, 2 \mathrm{H})$; 7.37-7.52 (m, 35H); 8.01-8.12 (m, 14H); $12.00(\mathrm{~s}, 1 \mathrm{H})$. ESI-MS [M + H] ${ }^{+}$: found for $\mathrm{C}_{105} \mathrm{H}_{76} \mathrm{O}_{22}, 1689.71$. HPLC purity $99.2 \%$.

\subsubsection{Synthesis of Octa-Cinnamoyl Hesperidin (Esp5)}

To a solution of hesperidin $(0.64 \mathrm{mmol})$ and DMAP (23.04 mmol) in $\mathrm{CH}_{2} \mathrm{Cl}_{2}(40 \mathrm{~mL})$, cinnamoyl chloride (17.28 mmol) was added. The reaction was stirring for $14 \mathrm{~h}$ at room temperature and then washed with $\mathrm{H}_{2} \mathrm{O}, \mathrm{NaHCO}_{3}$ and Brine. The combined organic phase was dried and evaporated under reduced pressure. The crude residue was purified by column chromatography (petroleum ether/ethyl acetate: 52/48). Esp5 was obtained as light yellow powder (final yield 74.07\%). ${ }^{1} \mathrm{H}$-NMR (DMSO) $\delta$ ppm: $1.20(\mathrm{t}, 3 \mathrm{H}) ; 3.10(\mathrm{~m}, 1 \mathrm{H}) ; 3.35(\mathrm{~m}, 2 \mathrm{H}) ; 3.58(\mathrm{~m}, 1 \mathrm{H}) ; 3.82(\mathrm{~s}, 3 \mathrm{H}) ; 4.28$ to $4.36(\mathrm{~m}, 2 \mathrm{H}) ; 5.32(\mathrm{t}, 2 \mathrm{H})$; 5.48 to $5.52(\mathrm{~m}, 2 \mathrm{H}) ;$,5.86 to $6.01(\mathrm{~m}, 4 \mathrm{H}) ; 6.28$ to $6.32(\mathrm{~d}, 8 \mathrm{H}) ; 6.41$ to $6.46(\mathrm{~d}, 2 \mathrm{H}) ; 6.78$ to $6.82(\mathrm{~d}, 1 \mathrm{H})$; $7.02(\mathrm{~m}, 2 \mathrm{H}) ; 7.18(\mathrm{~d}, 1 \mathrm{H}) ; 7.50$ to $7.56(\mathrm{~m}, 16 \mathrm{H}) ; 7.61$ to $7.64(\mathrm{~m}, 8 \mathrm{H}) ; 7.70$ to $7.78(\mathrm{~d}, 8 \mathrm{H}) ; 7.95$ to $8.02(\mathrm{~m}$, $16 \mathrm{H})$. ESI-MS $[\mathrm{M}+\mathrm{H}]^{+}$: found for $\mathrm{C}_{100} \mathrm{H}_{82} \mathrm{O}_{23}, 1652.70$. HPLC purity $98.8 \%$. 


\subsection{Determination of $\log P$}

The determination of the partition ratio $(\log P)$, was calculated as the logarithm of the concentration of substance that was in octanol and water. A test was carried out in a mixture of octanol and water ( $\mathrm{pH} 12$ ) in 1:1 ratio at room temperature. The biphasic system was stirred for $30 \mathrm{~min}$ and then centrifuged for $10 \mathrm{~min}(4000 \mathrm{rpm})$. An exact volume of each phase was analyzed with a spectrophotometer $(\lambda \max$ fixed for each single compound). LogP is the result of the following expression:

$$
\log \mathrm{P}=\log 10[\mathrm{mg} / 20 \mathrm{~mL}] \text { octanol } /[\mathrm{mg} / 20 \mathrm{~mL}] \mathrm{H}_{2} \mathrm{Où}
$$

\subsection{Antioxidant Assays}

\subsubsection{PCL Test (Photochemiluminescence)}

PCL assay was performed using the Popov and Lewin method [33]. This test permitted us to measure the antioxidant capacity of a compound with a Photochem ${ }^{\circledR}$ apparatus (Analytik Jena, Leipzig, Germany) against superoxide anion radicals generated from Luminol, a photo-sensitizer, when exposed to UV light (Double Bore ${ }^{\circledR}$ phosphor lamp, output $351 \mathrm{~nm}, 3 \mathrm{~m} \mathrm{Watt} / \mathrm{cm}^{2}$ ). The antioxidant activity of a liposoluble substance could be observed using the ACL (Antioxidant Capacity of Liposoluble substance) kit provided by the manufacturer [34]. Standard Trolox solution and Luminol reagent were prepared according to the protocol. An antioxidant molecule generated a kinetic light emission curve, monitored for $180 \mathrm{~s}$ and expressed as micromoles of Trolox per gram of compound. The areas under the curves were calculated using the PCLsoft control and analysis software.

\subsubsection{DPPH Test (Diphenylpicrylhydrazyl)}

DPPH assay was carried out using method proposed by Wang et al. [35]. At $0.75 \mathrm{~mL}$ of each molecule tested, $1.5 \mathrm{~mL}$ of DPPH methanolic solution was added. Each sample was tested in absorbance using a spectrophotometer UV-VIS at $517 \mathrm{~nm}$. The radical-scavenging activity was expressed as inhibition ratio of initial concentration of DPPH radical. For the best interpretation of the results, each compound was tested at a concentration able to cause $50 \%$ of the radical inhibition. DPPH values were expressed as $\mu \mathrm{mol}$ equivalents of Trolox for each gram of product.

\subsubsection{FRAP Assay (Ferric Reducing Antioxidant Power)}

FRAP assay was made according to the modified protocol described by Guihua et al. [36]. Each sample was dissolved with an appropriate solvent (water and/or methanol) to evaluate its ability in reducing ferric. Three solution were freshly prepared and then mixed to obtain the reagent for analysis: Acetate buffer $\mathrm{pH} 3.6,2,4,6$-tripyridyl-s-triazine (TPTZ) in $\mathrm{HCl}$, and ferric chloride $20 \mathrm{mM}$, in the ratio 10:1:1, respectively. $0,11 \mathrm{~mL}$ of each sample solution or solvent (blank) was added to $1,9 \mathrm{~mL}$ of the reagent. The standard used for the calibration curve was Trolox. The absorbance was measured at $593 \mathrm{~nm}$ after $10 \mathrm{~min}$ of incubation in the dark at $37^{\circ} \mathrm{C}$.

\subsection{Antifungal Activity}

\subsubsection{Microorganisms}

The dermatophytes used were Arthroderma cajetani Ajello, CBS 495.70 strain; Epidermophyton floccosum (Hartz) Langerone Milochevitch, CBS 358.93 strain; Trichophyton violaceum Malmsten, CBS 459.61 strain; Trichophyton tonsurans Malmsten, CBS 483.76 strain, Trichophyton mentagrophytes (Robin) Blanchard, CBS 160.66 strain; Microsporum canis Bodin CBS 4727 strain; Nannizzia gypsea (Bodin) Guiart et Grigoraki CBS 286.63 strain purchased by the Centraal Bureau voor Schimmelcultures (CBS), Baarn, Netherlands; Trichophyton rubrum (Castellani) Sabouraud IHME 4321; Microsporum gypseum (Bodin) Guiarte Grigorakis IHME 3999 from Institute of Hygiene and Epidemiology-Mycology (IHME, 
Brussels, Belgium). Cultures were maintained at $4{ }^{\circ} \mathrm{C}$ as agar slants, on Sabouraud Dextrose Agar (SDA, Sigma-Aldrich SRL, Milan, Italy).

\subsubsection{Antifungal Inhibition Growth Test}

Antifungal activity was determined as follows. Each test substance was dissolved in dimethylsulfoxide (DMSO) and aseptically mixed with sterile medium (SDA) at $45^{\circ} \mathrm{C}$ in order to obtain two different concentrations, 20 and $100 \mu \mathrm{g} / \mathrm{mL}$. The DMSO concentration in the final solution was adjusted to $0.1 \%$. The same concentration of DMSO $(0.1 \% v / v)$ was used to prepare the controls. For experiments, cultures were obtained by transplanting mycelium disks (10 mm diameters) from a single mother culture in the stationary phase. Before starting, mycelia were incubated on SDA on thin sheets of cellophane at $26 \pm 1{ }^{\circ} \mathrm{C}$ until the logarithmic growth phase. Subsequently, the cultures were transferred to Petri plates with media containing 20 or $100 \mu \mathrm{g} / \mathrm{mL}$ of the single substance and incubated under growth conditions.

The fungal growth was evaluated daily by measuring colony diameters (in millimeters) for seven days from the treatment onset [37]. The percentage of inhibition is calculated according to the following equation:

$$
\text { Percentage of relative inhibition }(\%)=\left[\left(\operatorname{dex}-\operatorname{dex}^{\prime}\right) / \operatorname{dex}\right] \times 100 \%
$$

where dex is the diameter of the mycelium in the control; and dex' is the diameter of the mycelium measured in the experiment plates at different concentrations.

\subsection{Preparation and Stability Test of Cosmetic Formulations}

In the present study, hesperidin and its five synthetic derivatives were formulated using the same base formulation (at a concentration of $0.3 \%$ ) and subjected to accelerated aging in an oven at $40{ }^{\circ} \mathrm{C}$ for 120 days. At each time point, the concentration of the active ingredient was monitored by HPLC analysis.

The formulation used is as follows:

INCI: Aqua, Glyceryl stearate citrate (8\%)e, Caprylic/Capric Triglyceride (6\%), Coco-caprylate (7\%), glycerin (5\%), cetearyl alcohol (2\%), Xanthan gum (0.2\%), Phenoxyethanol and Ethylhexylglycerin (1\%).

For each molecule analyzed, a standard $\mathrm{O} / \mathrm{W}$ (oil/water) emulsion was prepared. Once the ingredients were carefully weighted, three different phases were prepared. Phase A (aqueous phase) and phase B (oil phase) were heated separately up to a temperature between 60 and $70^{\circ} \mathrm{C}$, and then the oil phase was added to the aqueous phase, under mechanical stirring. During the subsequent cooling phase of the emulsion, maintained in continuous agitation, the compound investigated $(0.3 \%)$ was added as a third step, to preserve it from possible thermal degradation. Finally, the emulsion was cooled and kept in the fridge until the next day for analysis. The final $\mathrm{pH}$ value of each emulsion was adjusted to 5.5 .

For the analytical method, a different mobile phase was chosen for each formulation (Table 1).

Table 1. Analytical parameters of HPLC analysis of hesperidin and its derivatives.

\begin{tabular}{cccccc}
\hline \multicolumn{5}{c}{ Analytical Conditions } \\
\hline Compound & \% Solvent A & \% Solvent B & Flow Rate $(\mathbf{m L} / \mathbf{m i n})$ & $\boldsymbol{\lambda}(\mathbf{n m})$ & Column Temperature $\left({ }^{\circ} \mathbf{C}\right)$ \\
\hline Hesperidin & 77 & 23 & 1.5 & 270 & 27 \\
Esp1 & 2 & 98 & 1.5 & 270 & 27 \\
Esp2 & 77 & 23 & 1.2 & 280 & 27 \\
Esp3, Esp5 & 5 & 95 & 1.2 & 280 & 27 \\
Esp4 & 55 & 45 & 1.2 & 280 & 27 \\
\hline
\end{tabular}




\subsection{Cell Cultures and Assays}

\subsubsection{K562 Cell Culture}

K562, human erythroleukemic cell line, was the first human immortalized myelogenous leukemia line isolated and characterized by Lozzio CB and Lozzio BB, from a patient with chronic myelogenous leukemia (CML) in blast crisis [38]. K562 cells were cultured in a humidified atmosphere of 5\% $\mathrm{CO}_{2}$, in RPMI-1640 medium (Lonza, Verviers, Belgium) supplemented with $10 \%$ fetal bovine serum (FBS; Biowest, Nuaillé, France), 50 units $/ \mathrm{mL}$ penicillin (Lonza, Verviers, Belgium) and $50 \mu \mathrm{g} / \mathrm{mL}$ streptomycin (Lonza, Verviers, Belgium) [39].

\subsubsection{Anti-Proliferative Activities}

The K562 cells were counted with the BECKMAN COULTER ${ }^{\circledR}$ Z2 (Beckman, Pasadena, CA, USA) to evaluate the possible anti-proliferative effect caused by the derivatives after 72 and $96 \mathrm{~h}$ from the treatment, when cells are in the log phase of growth. Preliminary tests were done to identify the $\mathrm{IC}_{50}$ on K562 cells: 25,000 cells/mL were seeded in 24-well plates and treated with hesperidin and synthetic analogues at different concentrations.

\subsubsection{Pro-Apoptotic Effects}

Annexin V and Dead Cell assays on K562 cell line, untreated and treated with increasing doses of the derivatives for three days, were performed with the Muse cell analyzer (Millipore, Billerica, MA, USA), according to the instructions supplied by the manufacturer. This procedure utilized Annexin V to detect PS (PhosphatidylSerine) on the external membrane of apoptotic cells. A dead cell marker was also used as an indicator of cell membrane structural integrity. Cells were first washed with sterile PBS 1X, second tripsinized and resuspended in the original medium, and finally diluted (1:2) with the one step addition of the Muse Annexin V and Dead Cell reagent. After incubation of $20 \mathrm{~min}$ at room temperature, cell samples were analyzed, using Triton $X 0.01 \%$, as positive control [40]. Data from prepared samples are acquired and recorded utilizing the Annexin V and Dead Cell Software Module (Millipore, Billerica, MA, USA). Four populations of cells were distinguished using this assay: Live, early apoptotic, late apoptotic, and dead cells.

\subsection{Statistical Evaluations}

Relative standard deviations and statistical significance (Student's $t$ test; $p \leq 0.05$ ) were given where appropriate for all data collected. One-way ANOVA and LSD post hoc Tukey's honest significant difference test were used for comparing the bioactive effects of different samples. All computations were made using the statistical software STATISTICA 6.0 (StatSoft Italia srl).

\section{Results and Discussion}

\subsection{Chemistry}

In order to extend potential applications of hesperidin, five derivatives were synthesized (Table 2). Different substituent groups were used to explore lipophilicity changes: We chose cyclic substituent and not with increasing steric hindrance. Obtained derivatives had none or one free hydroxyl phenolic group in order to evaluate the differences in terms of biological activity and stability. Esterification reactions were carried out using different substituents with 4-dimethylaminopyridine (DMAP) in $\mathrm{CH}_{2} \mathrm{Cl}_{2}$ (Scheme 1) [32]. All derivatives were obtained by the same synthetic procedure, but they were purified with different methods. 
Table 2. Synthetic derivatives of hesperidin.

\begin{tabular}{cccc}
\hline Compounds & $\mathbf{R}$ & $\mathbf{R}_{\mathbf{1}}$ & $\mathbf{R}_{\mathbf{2}}$ \\
\hline Esp1 & tert-butyl-acetyl & $-\mathrm{H}$ & tert-butyl-acetyl \\
Esp2 & cyclo-hexyl-acetyl & $-\mathrm{H}$ & cyclo-hexyl-acetyl \\
Esp3 & benzoyl & $-\mathrm{H}$ & benzoyl \\
Esp4 & naphthoyl & $-\mathrm{H}$ & naphthoyl \\
Esp5 & cinnamoyl & cinnamoyl & cinnamoyl \\
\hline
\end{tabular}

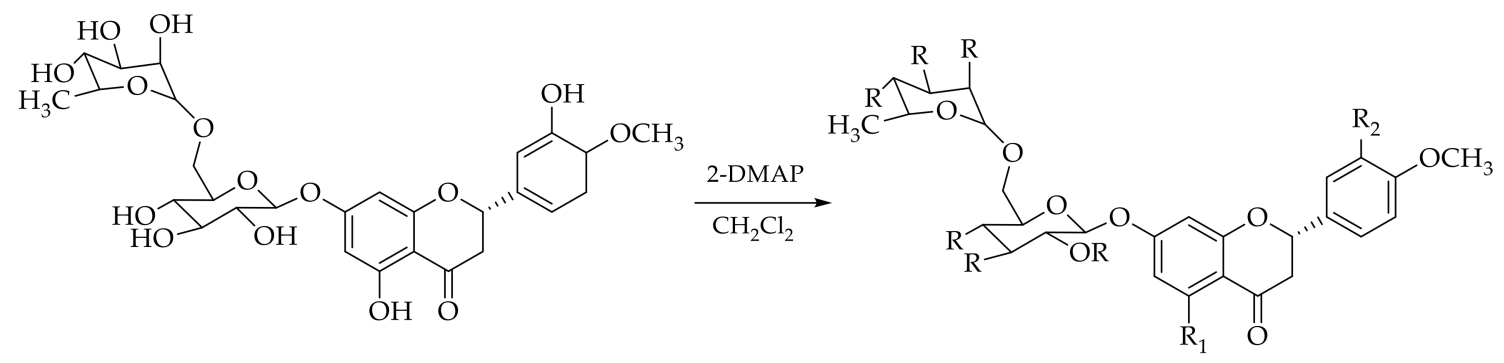

Scheme 1. Synthetic procedure of Esp1-Esp5.

\section{2. $\log P$ Values}

The partition ratio $(\log P)$, was calculated in order to evaluate changes in the lipophilic properties of the molecules induced by derivatizations. LogP values (Table 3) confirmed the increased lipophilicity of synthetic derivatives than hesperidin that had a negative $\log \mathrm{P}$ value.

Table 3. $\log P$ values of hesperidin and its synthetic derivatives.

\begin{tabular}{cc}
\hline Compounds & $\log \mathbf{P}^{[*]}$ \\
\hline Hesperidin & -0.87 \\
Esp1 & 1.38 \\
Esp2 & 0.40 \\
Esp3 & 2.04 \\
Esp4 & 1.08 \\
Esp5 & 1.04 \\
${ }_{[*]} \operatorname{LogP}=\log 10[\mathrm{mg} / 20 \mathrm{~mL}]$ loctanol $/[\mathrm{mg} / 20 \mathrm{~mL}] \mathrm{H}_{2} \mathrm{O}$.
\end{tabular}

\subsection{Antifungal Activity}

Recent studies have shown that a particular flavonoid's antimicrobial activity is correlated with its lipophilicity. Indeed, a quantitative structure-activity relationship (QSAR) study has shown that the activity of these compounds can be related to the hydrophobicity of the molecules themselves (CLogP) and to the presence of substituents in particular positions. The investigation of our derivatives on antifungal activity is based on this scientific evidence [41]. Taking into consideration the possible application as a multifunctional ingredient for dermo-cosmetic applications, antifungal activity of hesperidin and its derivatives were tested on six dermatophytes by the diffusion method in Sabouraud Dextrose Agar (SDA), in comparison with the well-known antifungal agent, Fluconazole. Antifungal activity of the natural molecule and its derivatives (data not shown) was not significative. The inhibition values were less than $20 \%$ for each compound on all dermatophytes, at the concentration of 20 and $100 \mu \mathrm{g} / \mathrm{mL}$. In several cases the compounds have shown hormone-like effects with a fungal growth higher than that of the control. $\mathrm{IC}_{50}$ values of Fluconazole on the same dermatophytes were between 3.5 to $37.2 \mu \mathrm{g} / \mathrm{mL}$, underlining the poor power of hesperidin and its derivatives on these microorganisms. 


\subsection{Antioxidant Activity}

The oxidative process is an important part for UV and pollution skin damage. However, it is responsible for the great instability of hesperidin in the dermo-cosmetic formulation due to accelerated degradation. To evaluate the antioxidant activity of semisynthetic compounds and hesperidin, three different in vitro tests were used. We chose to test the natural compound and its derivatives against different radicals (DPPH, FRAP and Photochemoluminescence assays) for a broader spectrum of antioxidant activity (Table 4).

Table 4. Antioxidant assays. Each value was the result of three different experiments (Mean $\pm \mathrm{SE}$ ).

\begin{tabular}{cccc}
\hline Compounds & $\begin{array}{c}\text { PCL } \\
\boldsymbol{\mu m o l T E} / \mathrm{g}\end{array}$ & $\begin{array}{c}\text { FRAP } \\
\boldsymbol{\mu m o l T E} / \mathrm{g}\end{array}$ & $\begin{array}{c}\text { DPPH } \\
\boldsymbol{\mu m o l T E} / \mathbf{g}\end{array}$ \\
\hline Hesperidin & $1068.63 \pm 1.12$ & $1255.32 \pm 4.04$ & $216.61 \pm 0.87$ \\
Esp1 & $2.16 \pm 0.09$ & $44.37 \pm 0.96$ & No activity \\
Esp2 & $1.14 \pm 0.50$ & $20.15 \pm 0.58$ & No activity \\
Esp3 & $22.58 \pm 2.92$ & $14.18 \pm 0.64$ & $6.03 \pm 0.31$ \\
Esp4 & $6.06 \pm 1.70$ & $19.61 \pm 0.84$ & No activity \\
Esp5 & $8.12 \pm 1.83$ & $18.19 \pm 0.77$ & No activity \\
\hline
\end{tabular}

As expected, hesperidin confirmed to be a potent antioxidant molecule, demonstrating a consistent activity against all of the three different radicals. On the other hand, being the new molecule precursor acylated to at least at one of the phenolic groups, they showed lower or no antioxidant activity in these in vitro assays, as expected. Esp1 demonstrated a two-fold increase in antioxidant activity $(44.37 \mu \mathrm{mol}$ $\mathrm{TE} / \mathrm{g}$ ) than the values of the other derivatives in FRAP test. Saturated alkyl chain (Esp1 and Esp2) exhibited similar antioxidant values in DPPH and PCL tests, like the aromatic ones. Esp5 was the only derivative which had both hydroxyl groups esterified. However, no significant difference in antioxidant activity with respect to the mono derivatives was found, demonstrating that the activity of the natural compound resides in the $\mathrm{OH}$ phenolic group on the aromatic ring in position two on bicycle croman-4-one, which was protected in all the obtained derivatives. In this respect, it is worth to note that the structure-activity relationship on antioxidant property of hesperidin, has not been deeply investigated so far [42].

\subsection{Stability Studies}

The stability of the newly synthesized compounds was evaluated in dermo-cosmetic formulations containing $0.3 \%(w / w)$ of each molecule. Finished formulations were subjected to accelerated aging in an oven at $40^{\circ} \mathrm{C}$ and monitored by HPLC for 120 days.

It is noteworthy (Figure 1) that the increase in lipophilicity greatly improved stability of hesperidin, thus making it possible to use the in finished formulations (less than $18 \%$ decrease after 120 days at $40{ }^{\circ} \mathrm{C}$ ). Indeed, hesperidin, which is susceptible to degradation, induced important changes also in the appearance of the formulation when introduced in significant amount in the finished products (color range went from yellow to brown after 30 days at $40{ }^{\circ} \mathrm{C}$ ). This latter occurrence explains why it is impossible to reach effective concentrations of free hesperidin in finished dermo-cosmetic formulations. On the contrary, each formulation, with its derivatives, remained uncolored until the end of its respective stability study.

\subsection{Antiproliferative Activity on Human Leukemic K562 Cells}

Hesperidin and its synthetic derivatives were tested to evaluate their potential antiproliferative effects on human chronic myelogenous leukemia K562 cell line, and demonstrated as a very useful experimental model system for the screening of potential antitumor drug [43]. This was done for two reasons: (a) To identify derivatives exhibiting antioxidant activity, with low effects on cell proliferation of eukaryotic cells and (b) to identify derivatives exhibiting both biological activities. Increasing 
amounts of hesperidin and its derivatives (from $1 \mu \mathrm{M}$ to $500 \mu \mathrm{M}$ ) were added to the cell cultures in order to analyze their effects on cell growth, evaluating the $\mathrm{IC}_{50}$ values after three and four days of cell culture. The results (Table 5) showed that the $\mathrm{IC}_{50}$ values of hesperidin and Esp2 are very similar (IC 50 values: $389.96 \pm 66.33 \mu \mathrm{M}$ and $376.13 \pm 45.53 \mu \mathrm{M}$, respectively), on the contrary we found that Esp4 and Esp5 are more active in inhibiting K562 cell growth (IC 50 values: $11.12 \pm 3.68 \mu \mathrm{M}$ and $21.68 \pm 4.36 \mu \mathrm{M}$, respectively). The data of Esp1 and Esp3 were not determined in detail since Esp1 and Esp3 were unstable during the test with clear evidence of precipitation (ppt) at concentrations exceeding $50 \mu \mathrm{M}$ (Esp1) and $400 \mu \mathrm{M}$ (Esp3).

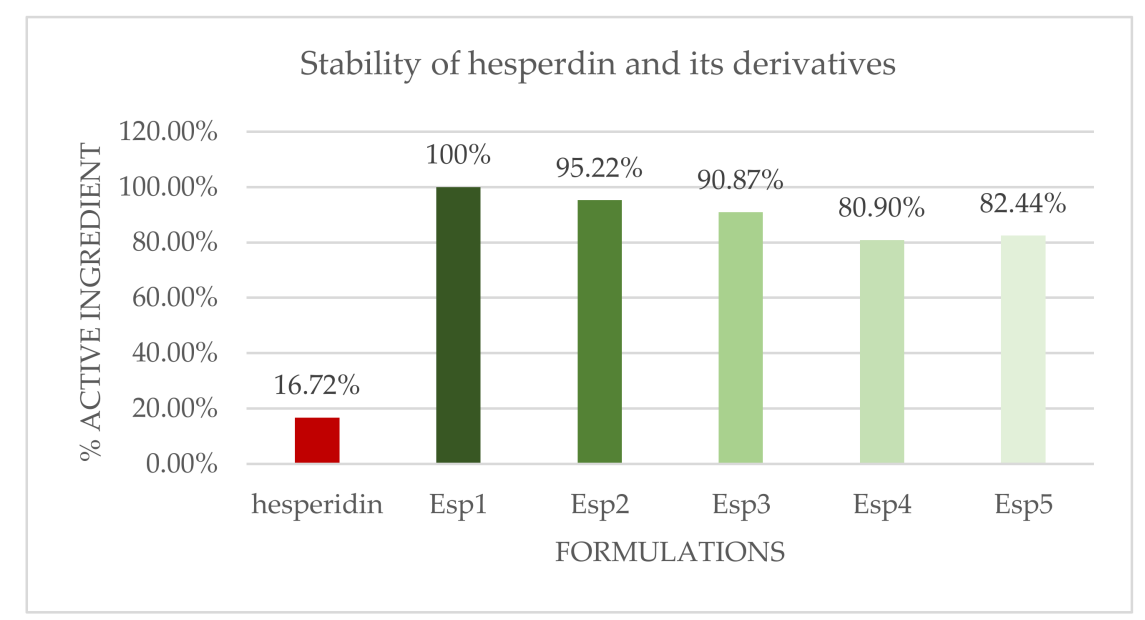

Figure 1. T120 Stability data of formulations with hesperidin and its derivatives (results are percentage decrease compared to T0).

Table 5. Effects of hesperidin and its derivatives on cell proliferation of K562 cells (the data are the mean of three independent experiments $\pm \mathrm{SD}$ ).

\begin{tabular}{cc}
\hline Compound & IC $_{\mathbf{5 0}}(\boldsymbol{\mu M})$ on K562 Cell Line \\
\hline Hesperidin & $389.96 \pm 35.49$ \\
Esp1 & $>50(\mathrm{ppt})$ \\
Esp2 & $376.13 \pm 32.29$ \\
Esp3 & $>400(\mathrm{ppt})$ \\
Esp4 & $11.12 \pm 1.97$ \\
Esp5 & $21.68 \pm 2.82$ \\
\hline
\end{tabular}

\subsection{Pro-Apoptotic Effect of Hesperidin and Its Analogues Esp1-5 on the K562 Cell Line}

Since anti-proliferative effects might be associated with the activation of apoptotic pathways, apoptosis was analyzed on the K562 cell line after treatment with hesperidin and its analogues for three days. Two different concentrations were used close to the relative $\mathrm{IC}_{50}$ values. All these concentrations were selected starting from the anti-proliferative effects shown in Table 5, except for Esp1 and Eps3, which were added at concentrations never exceeding the maximum concentrations used for these hesperidin analogues in the cell proliferation assays reported in Table 5. This was conducted in consideration of their already discussed precipitation effects in the aqueous medium, requiring the use of concentration values lower than their solubility limit. Table 6 shows the obtained results on the pro-apoptotic effects of these compounds, using the assay system, which enables the identification of early and late apoptosis stage, after comparison to untreated control cells (C-). The data shown in Table 6 originated from the analysis of the corresponding Muse Analyzer plots, after $72 \mathrm{~h}$ of treatment (representative results shown in Figure 2).

Among the tested compounds, the most interesting response was found when hesperidin and Esp2 were employed. Both of them were found to exert a very important and relevant activity, inducing 
apoptosis (when total apoptotic cells were considered) in more than $30 \%$ and $50 \%$ of the total cell population, respectively. The most interesting data obtained highlighted the shift caused by Esp2 of almost all the population to early apoptotic cells (Figure 2A) (Annexin-V positive, PI negative). Moreover, Esp5 seems to induce a slight pro-apoptotic effect (11.60\%). Among the anti-proliferative hesperidin analogues (see Table 4), a clear increment of late apoptotic cells was found with Esp5. For all three active derivatives, it is evident that a dose-dependent apoptosis increased, though it possible to observe some differences: Hesperidin and Esp5 are able to induce late apoptosis in the K562 cells in $72 \mathrm{~h}$, while Esp2, that possess the more evident pro-apoptotic effect, stimulates early apoptosis (Table 5 and Figure 2A).

Table 6. Pro-apoptotic activity (\%) of hesperidin and semi-synthetic analogues on K562 cells.

\begin{tabular}{ccccc}
\hline Compound & Live Cells (\%) & $\begin{array}{c}\text { Early Apoptotic } \\
\text { Cells (\%) }\end{array}$ & $\begin{array}{c}\text { Late Apoptotic } \\
\text { Cells (\%) }\end{array}$ & $\begin{array}{c}\text { Total Apoptotic } \\
\text { Cells (\%) }\end{array}$ \\
\hline C- (untreated cells) & 94.35 & 1.65 & 3.15 & 4.80 \\
Hesperidin $300 \mu \mathrm{M}$ & 74.05 & 3.50 & $\mathbf{2 1 . 6 5}$ & $\mathbf{2 5 . 1 5}$ \\
Hesperidin $400 \mu \mathrm{M}$ & 68.20 & 4.20 & $\mathbf{2 6 . 8 5}$ & $\mathbf{3 1 . 0 5}$ \\
Esp1 20 $\mu \mathrm{M}$ & 94.00 & 1.65 & 3.50 & 5.15 \\
Esp1 $50 \mu \mathrm{M}$ & 95.20 & 1.65 & 2.55 & 4.20 \\
Esp2 $300 \mu \mathrm{M}$ & 96.15 & 1.20 & 2.25 & 3.45 \\
Esp2 $400 \mu \mathrm{M}$ & 40.20 & 53.20 & 5.50 & 58.70 \\
Esp3 $200 \mu \mathrm{M}$ & 90.70 & 2.60 & 6.05 & 4.20 \\
Esp3 $400 \mu \mathrm{M}$ & 95.45 & 1.25 & 2.95 & 8.65 \\
Esp4 $5 \mu \mathrm{M}$ & 96.45 & 1.05 & 1.70 & 2.75 \\
Esp4 $10 \mu \mathrm{M}$ & 93.15 & 2.40 & 3.85 & 6.25 \\
Esp5 $10 \mu \mathrm{M}$ & 92.35 & 1.65 & 5.05 & 6.70 \\
Esp5 $20 \mu \mathrm{M}$ & 87.40 & 2.00 & 9.60 & 11.60 \\
\hline
\end{tabular}

This rather unexpected finding was confirmed in five different independent experiments aimed at comparing hesperidin and Esp2. The data obtained are reported in Figure $2 \mathrm{~B}$ and give clear evidence that, while $400 \mu \mathrm{M}$ hesperidin induced late apoptosis, $400 \mu \mathrm{M}$ Esp2 was able to induce only early apoptosis, characterized by the alteration of the charge ratio of the membrane causing Phosphatidylserine (PS) to be exposed to the cell surface. In the case of Esp2 treatment (unlike the treatment with hesperidin) this is not associated with disruption of the cellular membrane integrity. In fact, most of the hesperidin-treated cells ( $34.89 \pm 12.17$ in five independent experiments) were found to be Annexin- $\mathrm{V}$ positive and propidium iodide (PI) negative, while the majority of Esp2 treated cells (44.52 \pm 8.59 in five independent experiments) were found to be Annexin-V positive, PI negative. This effect is highly significant $(p<0.001)$. The induction of early apoptosis (but not of late apoptosis) was confirmed by forcing the system employing Esp2 at $700 \mu \mathrm{M}$. In this case, the \% of early apoptotic cells increased, in five independent experiments, to $83.68 \pm 5.16$ (data not shown), the \% of late apoptotic cells being $8.96 \pm 1.51$.

The data shown in Figure 2 suggest that hesperidin and Esp2 are potent inducers of apoptosis, but exhibit a sharply different mechanism of action, leading to activation of the early apoptosis pathway (Esp2) or to late apoptosis (hesperidin). Further experiments are necessary to understand the molecular basis of this differential effect. 
A

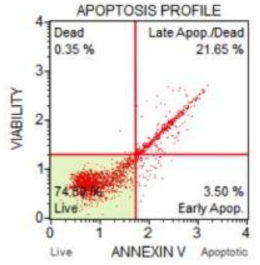

Hesperidin $300 \mu \mathrm{M}$

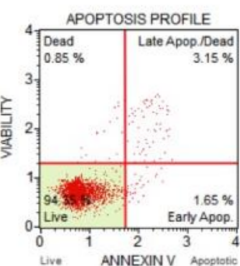

C-

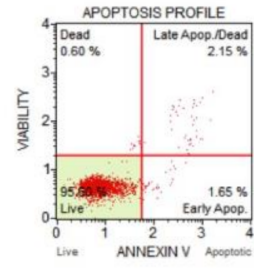

DMSO

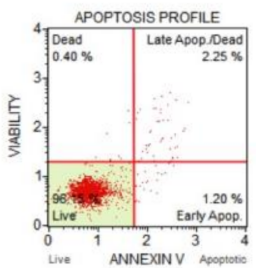

Esp2 $300 \mu \mathrm{M}$

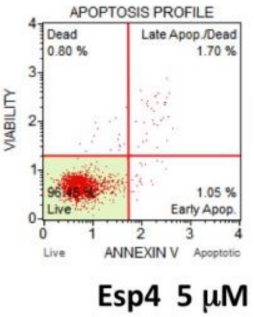

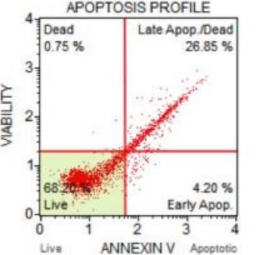

Hesperidin $400 \mu \mathrm{M}$

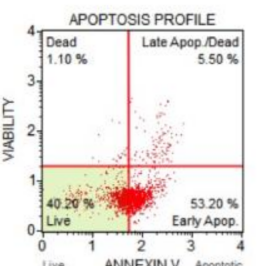

Esp2 $400 \mu \mathrm{M}$

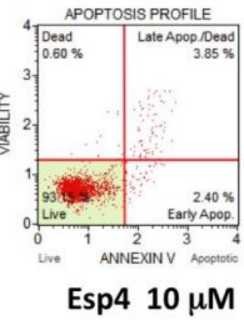

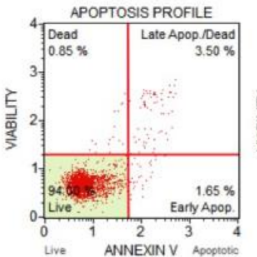

Esp1 $20 \mu \mathrm{M}$

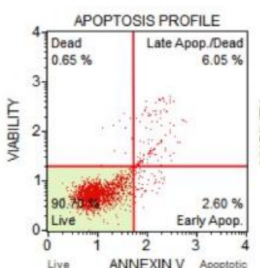

Esp3 $200 \mu \mathrm{M}$

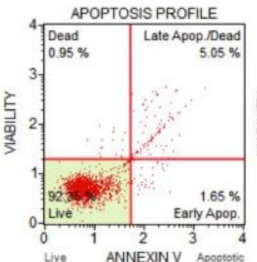

Esp5 $10 \mu \mathrm{M}$

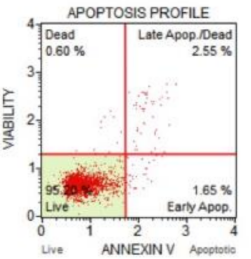

Esp1 $50 \mu \mathrm{M}$

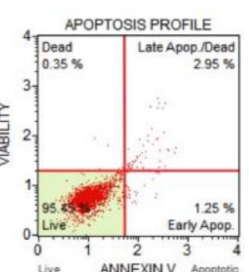

Esp3 $400 \mu \mathrm{M}$

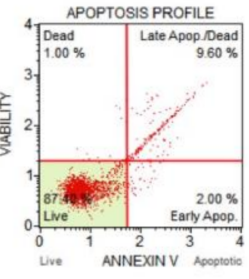

Esp5 $20 \mu \mathrm{M}$

B

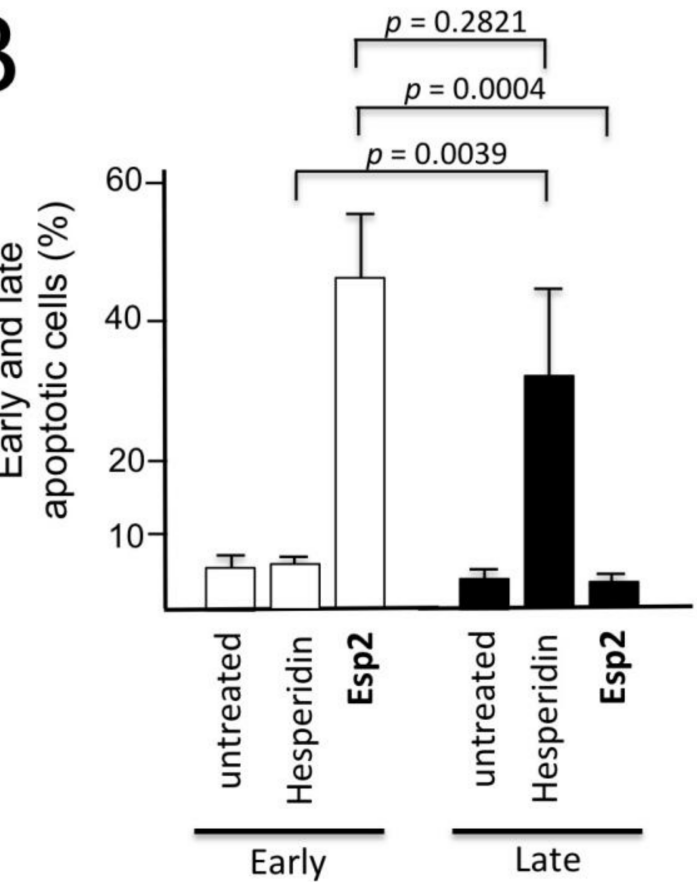

C

$p=0.1431$
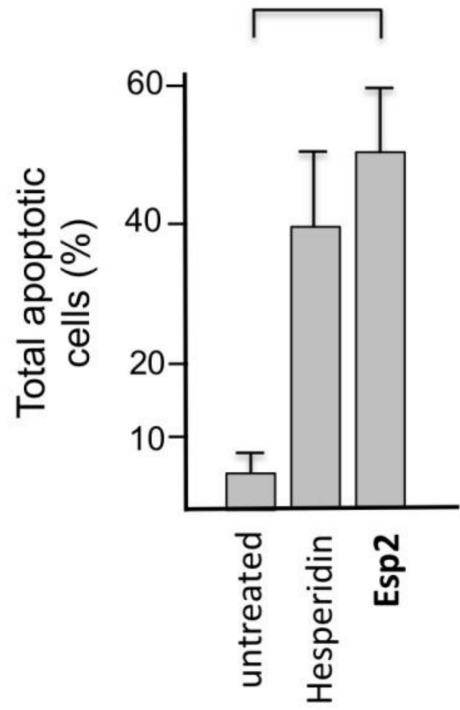

Figure 2. Annexin-V assays were performed on $\mathrm{K} 562$ cells treated for $72 \mathrm{~h}$ with the indicated concentrations of hesperidin and semi-synthetic analogues. (A) Representative examples showing that the best effects (total apoptosis $>30 \%$ ) on K562 cells treated with the hesperidin and its derivative Esp2 are here reported in comparison with untreated cells (negative control, C-). Also Esp5 demonstrated to induce late apoptosis $(11.60 \%)$. (B,C) Summary of the results obtained from five independent experiments. K562 cells were treated for $72 \mathrm{~h}$ with $400 \mu \mathrm{M}$ hesperidin and Esp2, as indicated and the apoptosis assay was performed as described in panel A. The results represent the average \pm S.D., of five independent experiments. 


\section{Conclusions}

The present preliminary study was designed in order to investigate the effects of lipidization of hesperidin, as a strategy to improve stability and the chance of inclusion in skin topical formulations of hesperidin derivatives. Five ester derivatives were prepared characterized by different substituting groups, ranging from a simple alkyl chain up to aromatic structures increasingly conjugated. Our results allow for us to hypothesize that synthetic derivatives can behave as pro-drugs of hesperidin, although further studies of bioavailability and determination of antioxidant activity in cells and tissues are necessary.

All synthetic derivatives proved to be much more stable in dermo-cosmetic formulations than the formulation containing hesperidin itself as active ingredient, confirming its applicability in products for dermo-cosmetic use. One obvious control was to verify the possible influence on activity, thus antiproliferative and pro-apoptotic effects of the hesperidin derivatives on eukaryotic cells were investigated. We therefore performed preliminary tests using erythroleukemic K562 cells as the experimental model system, since this cell line has been extensively used for these analyses. The results obtained indicated that Esp3 exhibited very low pro-apoptotic and anti-proliferative effects (Table 5 and Figure 2), while maintaining strong anti-oxidant activity (Table 4). Some derivatives exhibited a multifunctional activity that can complement, in a preventive way, the dermo-cosmetic application. Indeed, during the K562-based preliminary screening, they were interesting candidates for a multifunctional approach, exhibiting, in addition to anti-oxidant activity, cell growth inhibitory and pro-apoptotic activity. This has the potential to have a significant impact, also when considering the known skin tumorigenesis inhibition of hesperidin [44], which drives attention towards this, and related compounds, as a possible preventive agent in the treatment of some human pathologies, such as UV induced neoplastic diseases [45], squamous cell carcinoma (SCC) [46], malignant melanomas [47], non-melanoma skin tumors [48], and psoriasis-associated skin cancers [49]. In this context, hesperidin derivatives should be tested on the several "in vitro" experimental model systems available for these pathologies [50,51], as well as on "in vivo" mouse models for skin cancers [52,53].

As far as the effects on apoptosis, hesperidin and the analogue Esp2 behave differently, since hesperidin induces activation of late apoptosis, while Esp2 induces only early apoptosis. This should be considered in dermo-cosmetics, given that Esp2 is expected to differentially influence gene expression when compared to hesperidin. In respect to anti-tumor treatment, while hesperidin might be proposed as such, Esp2 might be used in combination with other anti-tumor drugs as proposed for other inducers of early stag apoptosis, such as fluoxetine [54] and carnorsol [55]. Combination therapy might be of interest since is based on the use of sub-optimal (and less toxic) concentrations of each agent.

Finally, the structure-activity relationship on antioxidant property of hesperidin, has not been deeply investigated so far and, due to the results here presented, further studies (in vitro and in vivo) are planned in order to deepen the knowledge of this interesting natural molecule, in particular its behavior towards normal and carcinogenic skin cells.

Author Contributions: Conceptualization, S.M., R.G.; Methodology, A.B. (Alessia Bino), I.L., A.B. (Anna Baldisserotto); Formal analysis, A.B. (Alessia Bino), I.L., E.D., A.B. (Anna Baldisserotto); Data curation, I.L., A.B. (Anna Baldisserotto); writing —original draft preparation, A.B. (Alessia Bino); writing—review and editing, A.B. (Anna Baldisserotto), S.M.; supervision, S.M., C.B.V.; funding acquisition, S.V., S.M.

Funding: This work was supported by the University of Ferrara (Bando FAR-2017 to C.B.V., FAR-2017 to I.L.) and Ambrosialab srl, Ferrara (Research Grant 2016).

Conflicts of Interest: The authors declare no conflict of interest.

\section{References}

1. King, A.; Young, G. Characteristics and Occurrence of Phenolic Phytochemicals. J. Am. Diet. Assoc. 1999, 99, 213-218. [CrossRef] 
2. Lin, D.; Xiao, M.; Zhao, J.; Li, Z.; Xing, B.; Li, X.; Kong, M.; Li, L.; Zhang, Q.; Liu, Y.; et al. An Overview of Plant Phenolic Compounds and Their Importance in Human Nutrition and Management of Type 2 Diabetes. Molecules 2016, 21, 1374. [CrossRef] [PubMed]

3. Banjarnahor, S.D.S.; Artanti, N. Antioxidant properties of flavonoids. Med. J. Indones. 2014, 23, $239-244$. [CrossRef]

4. Kostyuk, V.; Potapovich, A.; Albuhaydar, A.R.; Mayer, W.; De Luca, C.; Korkina, L. Natural Substances for Prevention of Skin Photoaging: Screening Systems in the Development of Sunscreen and Rejuvenation Cosmetics. Rejuvenation Res. 2018, 21, 91-101. [CrossRef] [PubMed]

5. Choi, S.H.; Choi, S.I.; Jung, T.D.; Cho, B.Y.; Lee, J.H.; Kim, S.H.; Yoon, S.A.; Ham, Y.M.; Yoon, W.J.; Cho, J.H.; et al. Anti-Photoaging Effect of Jeju Putgyul (Unripe Citrus) Extracts on Human Dermal Fibroblasts and Ultraviolet B-induced Hairless Mouse Skin. Int. J. Mol. Sci. 2017, 25, 2052. [CrossRef] [PubMed]

6. Xie, Y.; Chen, J.; Xiao, A.; Liu, L. Antibacterial Activity of Polyphenols: Structure-Activity Relationship and Influence of Hyperglycemic Condition. Molecules 2017, 6, 1913. [CrossRef] [PubMed]

7. Hodgson, R.W. History, world distribution, botany and varieties. In The Citrus Industry; Reuther, W., Webber, H., Batchelor, L., Eds.; University of California Press: Berkeley, CA, USA, 1967; pp. 431-591.

8. Fluckinger, F.A.; Hanbury, D. Pharmacographia-A History of the Principle Drugs of Vegetable Origin; International Book Distributors: Delhi, India, 1986; pp. 104-105. [CrossRef]

9. Chen, X.M.; Tait, A.R.; Kitts, D.D. Flavonoid composition of orange peel and its association with antioxidant and anti-inflammatory activities. Food Chem. 2017, 218, 15-21. [CrossRef]

10. Ratty, A.K.; Das, N.P. Effects of flavonoids on nonenzymatic lipid peroxidation: Structure-activity relationship. Biochem. Med. Metab. Biol. 1988, 39, 69-79. [CrossRef]

11. Ahmadi, A.; Shadboorestan, A. Oxidative stress and cancer; the role of hesperidin, a citrus natural bioflavonoid, as a cancer chemoprotective agent. Nutr. Cancer 2016, 68, 29-39. [CrossRef]

12. Jeong, H.; Phan, A.N.H.; Choi, J.W. Anti-cancer Effects of Polyphenolic Compounds in Epidermal Growth Factor Receptor Tyrosine Kinase Inhibitor-resistant Non-small Cell Lung Cancer. Pharmacogn. Mag. 2017, 13, 595-599. [CrossRef]

13. Montanari, A.; Chen, J.; Widmer, W. Citrus flavonoids: A review of past biological activity against disease. Discovery of new flavonoids from Dancy tangerine cold pressed peel oil solids and leaves. Adv. Exp. Med. Biol. 1998, 439, 103-116. [PubMed]

14. Wolfram, J.; Scott, B.; Boom, K.; Shen, J.; Borsoi, C.; Suri, K.; Grande, R.; Fresta, M.; Celia, C.; Zhao, Y.; et al. Hesperetin Liposomes for Cancer Therapy. Curr. Drug. Deliv. 2016, 13, 711-719. [CrossRef] [PubMed]

15. Ahmad, S.; Alam, K.; Hossain, M.M.; Fatima, M.; Firdaus, F.; Zafeer, M.F.; Arif, Z.; Ahmed, M.; Nafees, K.A. Anti-arthritogenic and cardioprotective action of hesperidin and daidzein in collagen-induced rheumatoid arthritis. Mol. Cell. Biochem. 2016, 423, 115-127. [CrossRef] [PubMed]

16. Zaghloul, R.A.; Elsherbiny, N.M.; Kenawy, H.I.; El-Karef, A.; Eissa, L.A.; El-Shishtawy, M.M. Hepatoprotective effect of hesperidin in hepatocellular carcinoma: Involvement of Wnt signaling pathways. Life Sci. 2017, 185, 114-125. [CrossRef] [PubMed]

17. Liu, D.; Wu, J.; Xie, H.; Liu, M.; Takau, I.; Zhang, H.; Xiong, Y.; Xia, C. Inhibitory effect of Hesperetin and Naringenin on human UDP-Glucuronosyltransferase enzymes: Implications for herbal-drug interactions. Biol. Pharm. Bull. 2016, 39, 2052-2059. [CrossRef] [PubMed]

18. Thilakarathna, S.H.; Rupasinghe, H.P.V. Flavonoid Bioavailability and Attempts for Bioavailability Enhancement. Nutrients 2013, 5, 3367-3387. [CrossRef] [PubMed]

19. Chuang, S.Y.; Lin, Y.K.; Lin, C.F.; Wang, P.W.; Chen, E.L.; Fang, J.Y. Elucidating the Skin Delivery of Aglycone and Glycoside Flavonoids: How the Structures Affect Cutaneous Absorption. Nutrients 2017, 9, 1304. [CrossRef] [PubMed]

20. Hultberg, B.; Sjoblad, S.; Ockerman, P.A. Glycosidases in human skin fibroblast cultures $\alpha$-fucosidase, $\alpha$-galactosidase, $\alpha$-glucosidase, $\beta$-mannosidase, and $\mathrm{N}$-acetyl- $\alpha$-glueosaminidase. Acta Paediatr. 1975, 64 , 123-131. [CrossRef]

21. Engen, A.; Maeda, J.; Wozniak, D.E.; Brents, C.A.; Bell, J.J.; Uesaka, M.; Aizawa, Y.; Kato, T.A. Induction of cytotoxic and genotoxic responses by natural and novel Quercetin glycosides. Mutat. Res. Genet. Toxicol. Environ. Mutagen. 2015, 784-785, 15-22. [CrossRef]

22. Souza, C.; de Freitas, L.A.; Maia Campos, P.M. Topical Formulation Containing Beeswax-Based Nanoparticles Improved in vivo Skin Barrier Function. AAPS Pharm. Sci. Tech. 2017, 18, 2505-2516. [CrossRef] 
23. Depieri, L.V.; Praça, F.S.; Campos, P.M.; Bentley, M.V. Advances in the bioanalytical study of drug delivery across the skin. Ther. Deliv. 2015, 6, 571-594. [CrossRef] [PubMed]

24. Alvarez-Figueroa, J.M.; Pessoa-Mahana, D.C.; Palavecino-González, E.M.; Mella-Raipán, J.; Espinosa-Bustos, C.; Lagos-Muñoz, M.E. Evaluation of the Membrane Permeability (PAMPA and Skin) of Benzimidazoles with Potential Cannabinoid Activity and their Relation with the Biopharmaceutics Classification System (BCS). AAPS Pharm. Sci. Tech. 2011, 12, 573-578. [CrossRef] [PubMed]

25. Herman, A.; Herman, A.P. Essential oils and their constituents as skin penetration enhancer for transdermal drug delivery: A review. J. Pharm. Pharmacol. 2015, 67, 473-485. [CrossRef] [PubMed]

26. Majumdar, S.; Srirangam, R. Solubility, Stability, Physicochemical Characteristics and In Vitro Ocular Tissue Permeability of Hesperidin: A Natural Bioflavonoid. Pharm. Res. 2009, 26, 1217-1225. [CrossRef] [PubMed]

27. Cao, R.; Xue, Y.; Strappe, P.; Blanchard, C.; Zhou, Z. Natural products derived from tea on the solubility of hesperidin by LC-TOF/MS and NMR. Int. J. Food Prop. 2017, 20 (Suppl. 1), S270-S278. [CrossRef]

28. Tozuka, Y.; Imono, M.; Uchiyama, H.; Takeuchi, H. A novel application of $\alpha$-glucosyl hesperidin for nanoparticle formation of active pharmaceutical ingredients by dry grinding. Eur. J. Pharm. Biopharm. 2011, 79, 559-565. [CrossRef] [PubMed]

29. Kilor, V.A. Design and development of novel microemulsion based topical formulation of Hesperidin. Int. J. Pharm. Pharm. Sci. 2015, 7, 238-245.

30. Vertuani, S.; Beghelli, E.; Scalambra, E.; Malisardi, G.; Copetti, S.; Dal Toso, R.; Baldisserotto, A.; Manfredini, S. Activity and stability studies of verbascoside, a novel antioxidant, in dermo-cosmetic and pharmaceutical topical formulations. Molecules 2011, 16, 7068-7080. [CrossRef]

31. Baldisserotto, A.; Malisardi, G.; Scalambra, E.; Andreotti, E.; Romagnoli, C.; Vicentini, C.B.; Manfredini, S.; Vertuani, S. Synthesis, antioxidant and antimicrobial activity of a new phloridzin derivative for dermo-cosmetic applications. Molecules 2012, 17, 13275-13289. [CrossRef]

32. Baldisserotto, A.; Vertuani, S.; Bino, A.; De Lucia, D.; Lampronti, I.; Milani, R.; Gambari, R.; Manfredini, S. Design, synthesis and biological activity of a novel Rutin analogue with improved lipid soluble properties. Bioorg. Med. Chem. 2015, 23, 264-271. [CrossRef]

33. Lewin, G.; Popov, I. Oxidants and Antioxidants Part B-Antioxidative Homeostasis: Characterization by Means of Chemiluminescent Technique. Methods Enzymol. 1999, 300, 437-456. [CrossRef]

34. Schlesier, K.; Harwat, M.; Böhm, V.; Bitsch, R. Assessment of antioxidant activity by using different in vitro methods. Free Radic. Res. 2002, 36, 177-187. [CrossRef] [PubMed]

35. Wang, M.; Li, J.; Rangarajan, M.; Shao, Y.; La Voie, E.J.; Huang, T.-C.; Ho, C.-T. Antioxidative phenolic compound from sage (salvia officinalis). J. Agric. Food Chem. 1998, 46, 4868-4873. [CrossRef]

36. Xu, G.; Ye, X.; Chen, J.; Liu, D. Effect of heat treatment on the phenolic compounds and antioxidant capacity of citrus peel extract. J. Agric. Food Chem. 2007, 55, 330-335. [CrossRef] [PubMed]

37. Romagnoli, C.; Baldisserotto, A.; Vicentini, C.B.; Mares, D.; Andreotti, E.; Vertuani, S.; Manfredini, S. Antidermatophytic Action of Resorcinol Derivatives: Ultrastructural Evidence of the Activity of Phenylethyl Resorcinol against Microsporum gypseum. Molecules 2016, 21, 1306. [CrossRef] [PubMed]

38. Lozzio, C.B.; Lozzio, B.B. Human chronic myelogenous leukemia cell-line with positive Philadelphia-chromosome. Blood 1975, 45, 321-334. [PubMed]

39. Lampronti, I.; Khan, M.T.; Borgatti, M.; Bianchi, N.; Gambari, R. Inhibitory Effects of Bangladeshi Medicinal Plant Extracts on Interactions between Transcription Factors and Target DNA Sequences. Evid.-Based Complement. Altern. Med. 2008, 5, 303-312. [CrossRef] [PubMed]

40. Lampronti, I.; Borgatti, M.; Vertuani, S.; Manfredini, S.; Gambari, R. Modulation of the expression of the pro-inflammatory IL-8 gene in cystic fibrosis cells by extracts deriving from olive mill waste water. Evid.-Based Complement. Altern. Med. 2013, 2013, 960603. [CrossRef]

41. Wu, T.; He, M.; Zang, X.; Zhou, Y.; Qiu, T.; Pan, S.; Xu, X. A structure-activity relationship study of flavonoids as inhibitors of E. coli by membrane interaction effect. Biochim. Biophys. Acta 2013, 1828, 2751-2756. [CrossRef]

42. Mishra, K. Structure-Activity Relationship of Antioxidative Property of Hesperidin. Int. J. Pharma. Erud. 2013, 2, 40-53. 
43. Khan, M.T.; Lampronti, I.; Martello, D.; Bianchi, N.; Jabbar, S.; Choudhuri, M.S.; Datta, B.K.; Gambari, R. Identification of pyrogallol as an antiproliferative compound present in extracts from the medicinal plant Emblica officinalis: Effects on in vitro cell growth of human tumor cell lines. Int. J. Oncol. 2002, 21, 187-192. [CrossRef] [PubMed]

44. Lee, K.A.; Lee, S.H.; Lee, Y.J.; Baeg, S.M.; Shim, J.H. Hesperidin Induces Apoptosis by Inhibiting Sp1 and Its Regulatory Protein in MSTO-211H Cells. Biomol. Ther. (Seoul) 2012, 20, 273-279. [CrossRef] [PubMed]

45. Fischer, N.; Seo, E.J.; Efferth, T. Prevention from radiation damage by natural products. Phytomedicine 2018, 47, 192-200. [CrossRef] [PubMed]

46. Waldman, A.; Schmults, C. Cutaneous Squamous Cell Carcinoma. Hematol. Oncol. Clin. N. Am. 2019, 33, 975-983. [CrossRef] [PubMed]

47. Rabbie, R.; Ferguson, P.; Molina-Aguilar, C.; Adams, D.J.; Robles-Espinoza, C.D. Melanoma subtypes: Genomic profiles, prognostic molecular markers and therapeutic possibilities. J. Pathol. 2018. [CrossRef] [PubMed]

48. Polini, B.; Digiacomo, M.; Carpi, S.; Bertini, S.; Gado, F.; Saccomanni, G.; Macchia, M.; Nieri, P.; Manera, C.; Fogli, S. Oleocanthal and oleacein contribute to the in vitro therapeutic potential of extra virgin oil-derived extracts in non-melanoma skin cancer. Toxicol. In Vitro 2018, 52, 243-250. [CrossRef] [PubMed]

49. Rajan, N.; Langtry, J.A. Generalized exacerbation of psoriasis associated with imiquimod cream treatment of superficial basal cell carcinomas. Clin. Exp. Dermatol. 2006, 31, 140-141. [CrossRef]

50. Zoschke, C.; Schilrreff, P.; Romero, E.L.; Brandner, J.M.; Schafer-Korting, M. Dendritic nanoparticles for cutaneous drug delivery-Testing in human skin and reconstructed human skin. Curr. Pharm. Des. 2015, 21, 2784-2800. [CrossRef]

51. Brauchle, E.; Johannsen, H.; Nolan, S.; Thude, S.; Schenke-Layland, K. Design and analysis of a squamous cell carcinoma in vitro model system. Biomaterials 2013, 34, 7401-7407. [CrossRef]

52. Saleh, J. Murine models of melanoma. Pathol. Res. Pract. 2018, 214, 1235-1238. [CrossRef]

53. Amberg, N.; Holcmann, M.; Glitzner, E.; Novoszel, P.; Stulnig, G.; Sibilia, M. Mouse models of nonmelanoma skin cancer. Methods Mol. Biol. 2015, 1267, 217-250. [CrossRef] [PubMed]

54. Ma, J.; Yang, Y.R.; Chen, W.; Chen, M.H.; Wang, H.; Wang, X.D.; Sun, L.L.; Wang, F.Z.; Wang, D.C. Fluoxetine synergizes with temozolomide to induce the CHOP-dependent endoplasmic reticulum stress-related apoptosis pathway in glioma cells. Oncol. Rep. 2016, 36, 676-684. [CrossRef] [PubMed]

55. Giacomelli, C.; Daniele, S.; Natali, L.; Iofrida, C.; Flamini, G.; Braca, A.; Trincavelli, M.L.; Martini, C. Carnosol controls the human glioblastoma stemness features through the epithelial-mesenchymal transition modulation and the induction of cancer stem cell apoptosis. Sci. Rep. 2017, 7, 15174. [CrossRef] [PubMed] 